\title{
Management Of Unstable Cervical Spine Injuries In Southern Iraq During OP TELIC
}

\author{
JH Bird, DP Luke, NJ Ward, MPM Stewart, PA Templeton
}

\begin{abstract}
\section{Introduction}

Cervical spine fractures and dislocations are uncommon injuries that can have serious neurological consequences. These injuries require adequate stabilisation to prevent further spinal cord injury during transfer between hospitals. Evacuation often requires a combination of road ambulance, helicopter and fixed wing aircraft from military hospitals. This paper outlines the neck injuries sustained during $O p$ Telic and discusses the need for Halo vests to be available at Role 3 .
\end{abstract}

\section{Methodology}

The MND(SE) Hospital databases were

Maj (Retd) JH Bird

MRCSEd

Department of

Orthopaedics

West Middlesex

University Hospital,

Twickenham Road,

Isleworth, TW7 6AF

Maj DP Luke MRCSEd RCDM

Selly Oak Road, Birmingham, B29 6JD

Maj NJ Ward RAMC

Royal Hospital Haslar,

Haslar Road, Gosport,

PO12 2AB

ColMPM Stewart

L/RAMC

Orthopaedic

Department

The James Cook

University Hospital,

Middlesborough,

TS4 3B

Email: stewartmpm@clara.net

Maj PA Templeton

FECS (Orth) RAMC

(V)

Orthopaedic Consultant

Department of

Orthaepic Surgery

The General Infirmary

at Leeds Great, George

Street,

Leeds, LS1 3EX

Email:

Peter.Templeton@leedssth.nhs.uk used to identify all casualties admitted with either a "Cervical" or "Neck" injury. The databases covered the period from 24 March 2003 until 15 April 2004. The diagnoses were categorised into minor and serious cervical spine injuries. We defined a serious cervical spine injury as either a fracture or dislocation. We looked at the discharge letters of all casualties evacuated to a Role 4 hospital to confirm whether the casualties had serious cervical spine injuries.

\section{Results}

Forty seven casualties were admitted and all were British except three, two Iraqi civilians and one US soldier. Thirty three duty, or discharged at the airhead on return to the UK. Fourteen casualties required hospital treatment. There were five serious cervical spine injuries over the study period which included one Hangman's fracture of $\mathrm{C} 2$, one flexion compression injury of $\mathrm{C} 5$, one flexion compression injury of $\mathrm{C} 7$, one unifacetal dislocation and one bifacetal dislocation.

\section{Conclusions}

Five casualties were treated at $\mathrm{MND}$ (SE) Hospital for serious injuries to the cervical spine. Two patients were transferred without Halo stabilisation after failing to obtain halos in Iraq. One casualty was kept until a Halo was flown out from the UK. casualties were returned to their unit for

\section{Recommendations}

All unstable cervical spine fractures should be stabilised with a Halo Vest prior to transfer from Role 3. Halo Rings and Vests should be available at Role 3 facilities.

\section{Introduction}

Cervical spine fractures and dislocations are uncommon injuries $(1,2)$ that can have serious neurological consequences. These injuries require adequate stabilisation to prevent further spinal cord injury during transfer between hospitals. Evacuation is usually by road ambulance in the UK, but often requires a combination of road ambulance, helicopter and fixed wing aircraft from military hospitals.

Evacuation of casualties from Iraq to the UK can take several days in order to allow for stabilisation of the casualty's general condition and organisation of an aeromedical evacuation flight. A combination of stiff collars, blocks, tape and/or skeletal traction have been used to maintain cervical spine immobilisation prior to evacuation up until recently.

This paper outlines the neck injuries sustained during Op Telic and discusses the

Echelons of Medical Support in the British Military Setting

\begin{tabular}{|l|l|}
\hline Role 1 & $\begin{array}{l}\text { Medical support inherent to a unit. } \\
\text { It comprises of physician managed } \\
\text { treatment to restore and stabilise } \\
\text { vital functions plus evacuation of } \\
\text { casualties from point of wounding. }\end{array}$ \\
\hline Role 2 & $\begin{array}{l}\text { Normally provided at Brigade and } \\
\text { Divisional level. Comprises } \\
\text { resuscitative surgery and stabilising } \\
\text { treatment plus evacuation from Role } \\
1 .\end{array}$ \\
\hline Role 3 & $\begin{array}{l}\text { Normally provided at Corps } \\
\text { level. (i.e. British Military Field } \\
\text { Hospitals) Comprises life and limb } \\
\text { saving surgery, hospitalisation and } \\
\text { evacuation from Role 2. }\end{array}$ \\
\hline Role 4 & $\begin{array}{l}\text { Normally provided in the UK. (i.e. } \\
\text { The Royal Centre for Defence } \\
\text { Medicine at Birmingham) } \\
\text { Comprises time consuming } \\
\text { definitive treatment \& rehabilitation } \\
\text { and strategic evacuation. Hospitals } \\
\text { may be civilian or military }\end{array}$ \\
\hline
\end{tabular}


need for Halo Vests at British Military Hospitals (Role 3) for the management of unstable cervical spine injuries.

\section{The Hospital}

Multinational Division (MND) South East (SE) Hospital is situated on a disused airfield approximately 40 minutes drive from Basra International Airport. It is constructed entirely of tented accommodation and consists of a maximum of 200 beds in 8 wards, although as few as 75 beds in 3 wards may be open depending on requirements. There is the capability to resuscitate 4 major trauma cases and operate on 2 casualties simultaneously. The medical staffing includes one Consultant General Surgeon, one Consultant Orthopaedic Surgeon, 2 Consultant Anaesthetists, one Consultant in Accident \& Emergency Medicine, one Consultant Physician plus 5 junior medical staff. The British Military Field Hospital provides Role 3 Medical Support for 14000 personnel including Coalition Forces (CF) and civilian contractors employed by MND(SE). In addition the hospital treats anyone injured by $\mathrm{CF}$, any injured detainees and any civilian with life or limb threatening injuries.

Since the end of the war in Iraq in April 2003, the MND(SE) Hospital has not been under any specific threat from land or air. There is now no urgency to evacuate a casualty to the UK with an unstable cervical spine injury without appropriate stabilisation.

\section{Purpose}

To study the incidence and management of potentially unstable cervical spine injuries in a recent Military Theatre of Operations.

\section{Aeromedical Evacuation}

Casualties are usually evacuated on a stretcher by helicopter from $\mathrm{MND}(\mathrm{SE})$ Hospital to Basra International Airport where they are flown back to RAF Brize Norton on a C17 Transport Aircraft. They are then transferred by road ambulance from RAF Brize Norton to RCDM (Royal Centre for Defence Medicine) Birmingham. The journey takes 13 hours from "door to door". If Hercules C130 Transport Aircraft are used for evacuation instead of jets, the trip can take up to 24 hours. During the flight the cervical spine is immobilised with a stiff collar and a vacuum pillow as there is no facility for traction. The Aeromedical Evacuation Team prefer the use of a Halo Ring and Vest System for immobilisation of serious neck injuries as it gives added security during any turbulence and makes skin care much easier.

\section{Methodology}

The MND(SE) Hospital databases in the Hospital Management Cell and the Aeromedical Evacuation Cell were used to identify all casualties admitted with either a "Cervical" or "Neck" injury. The present databases started at the establishment of the hospital on 24 March 2003, shortly after the beginning of Op Telic. The study period ended on 15 April 2004. Casualties from both databases were combined to make one list. Casualty details included serial number, date of admission, diagnosis, spinal immobilisation, disposal, and definitive treatment were recorded. The diagnoses were categorised into closed soft tissue injuries, penetrating soft tissue injuries, burns, infections, brachial neuralgia, and serious cervical spine injuries. For the purpose of this paper we defined a serious cervical spine injury as either a fracture or dislocation diagnosed with radiographs and transferred to a Role 4 Hospital for further investigation and treatment. We reviewed the discharge letters of all casualties evacuated to a Role 4 Hospital to confirm whether the casualties had serious cervical spine injuries.

\section{Results}

- 4870 casualties were admitted to the MND (SE) Hospital over the study period.

- 47 casualties were identified as having either a "neck" or a "cervical" injury.

- All of the casualties were British except 2 Iraqis and 1 American.

- 33 casualties were returned to their unit for duty or discharged at the airhead on return to the UK.

- 14 required hospital treatment;

- 5 at The Princess Mary Hospital Akrotiri, Cyprus.

- 6 at RCDM in Birmingham.

- 2 at Basra General Hospital.

- 1 at the US Hospital in Baghdad.

- Of the 14 requiring hospital treatment;

- 6 had soft tissue 'whiplash' injuries.

- 2 had penetrating injuries to the neck that had no bony involvement.

- one burn.

- The remaining 5 had a serious cervical spine injury as defined above, they will be discussed in detail below.

\section{Case 1}

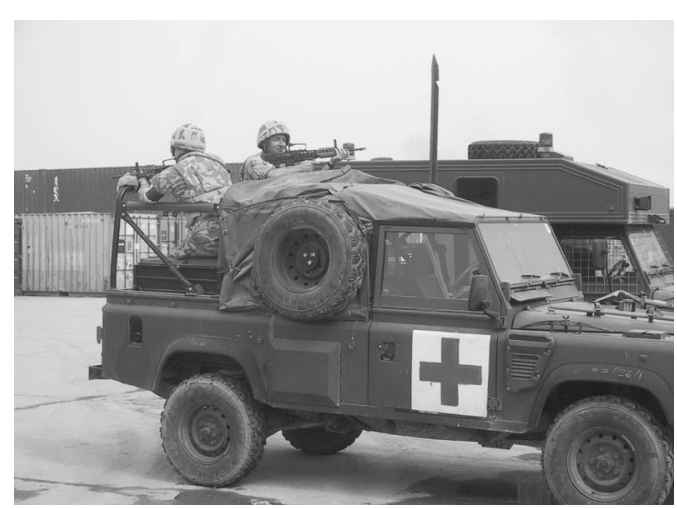

Fig 1. Armed figures in Army Land Rover. 
A 24 year old British male soldier sustained a Flexion / Compression fracture of C5. He was providing 'Top Cover' in an Army Land Rover. This involves two armed soldiers standing in the rear of the vehicle with their shoulders above the level of the roof (Figure 1). A girder on a low bridge struck the top of his helmet, forcing him down into the floor of the Land Rover. The second 'Top Cover' was struck by the girder on the back of the head and was killed instantly. The first soldier walked around for one hour before he noticed neck stiffness. At that point he was placed on a spinal board and his neck immobilised with a stiff collar, sandbags and tape. $\mathrm{He}$ was evacuated by helicopter to $\mathrm{MND}$ (SE) Hospital where he was noted to have tenderness on the right side of his neck but not in the midline. Cervical spine X-rays revealed a coronal fracture of the body of C5 with approximately 2 to $3 \mathrm{~mm}$ retropulsion of the middle column into the canal and 1 to 2 $\mathrm{mm}$ anterior displacement of the anterior column (Figure 2). The anteroposterior view did not reveal any interpedicular widening. Neurological examination revealed a brisk left knee jerk but no muscle weakness or sensory loss in any limb. Rectal examination was normal. Cervical spine precautions were continued and he was admitted for bed rest and $\log$ rolling. The following day his reflexes returned to normal. The Neurosurgeons at RCDM Birmingham recommended immobilisation of the cervical spine in a Halo Vest prior to evacuation to the UK. A Halo Vest and Ring of appropriate size were flown out from the UK and applied under local anaesthetic. Three days after injury, he was safely evacuated to RCDM Birmingham where the fracture was definitively managed in the same Halo Vest.

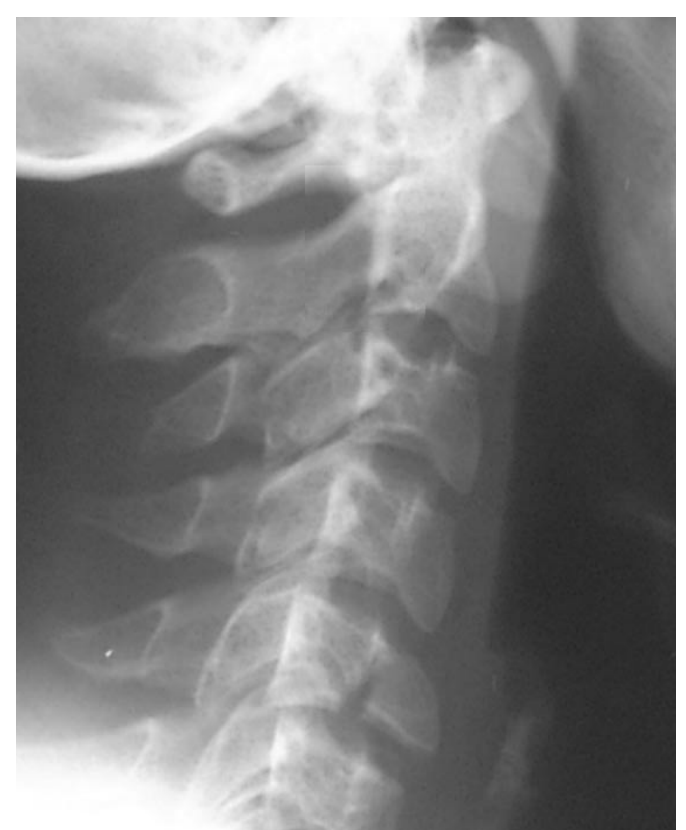

Fig 2. X-ray showing coronal fracture.

Case 2

A 23 year old British male soldier tripped on the top of an 'iso container' while carrying equipment. He fell forwards landing on his head resulting in a brief loss of consciousness. Having regained consciousness he was brought to $\mathrm{MND}(\mathrm{SE})$ Hospital immobilised on a spinal board with a GCS (Glasgow Coma Scale) of 13. He complained of central neck pain with tenderness and limitation of movement on examination. He had normal neurology in his upper and lower limbs. Radiographs revealed a C5 on C6 unifacetal dislocation with no associated fracture (Figure 3). Initially he was immobilised in a stiff collar, sandbags and tape until skull callipers were applied under local anaesthetic. Traction was applied, however, reduction proved impossible. The casualty remained in skull traction until evacuated by air to RCDM Birmingham. In-flight traction was not available and, therefore, a vacuum mattress and stiff collar were used. On arrival at RCDM Birmingham, a further attempt at closed reduction failed. Open reduction was performed under general anaesthesia and a Halo was applied. He was discharged home with the Halo which was used for definitive treatment. Prior to his 6 week review appointment, the casualty was readmitted to a local hospital with a reduced level of consciousness. A chronic sub-dural haematoma was diagnosed and drained by the local neurosurgeons who have taken over his follow up.

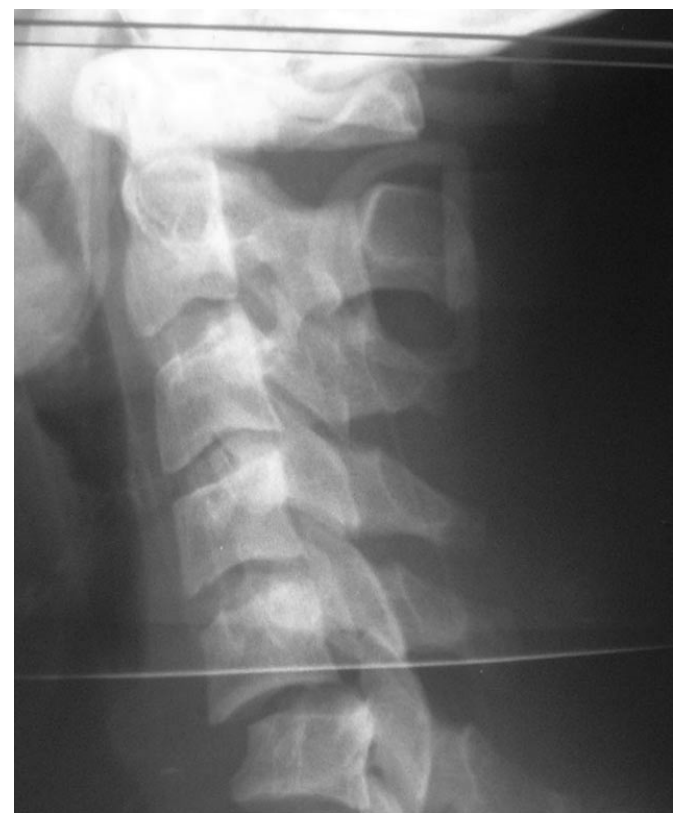

Fig 3. Radiographs showing a C5 on C6 unifacetal dislocation.

\section{Case 3}

A 42 year old Iraqi male civilian was injured as an unrestrained passenger in a vehicle that rolled over after being ambushed by gunmen. The driver had been shot and lost control of the vehicle. This gentleman suffered numerous injuries which were identified by primary and secondary surveys. These injuries included a C2 'Hangman's' fracture (Figure 4), a humeral fracture, a stable pelvic 
fracture and numerous fractured ribs. $\mathrm{He}$ had no neurological deficit on examination. His management at MND (SE) Hospital was non-operative. His neck was immobilised in a stiff collar with sandbags. His humeral fracture was managed with a plaster U-Slab and his pelvic fracture required no fixation. $\mathrm{He}$ was transferred to Basra General Hospital with his neck immobilised in a stiff collar and a vacuum pillow. The local Iraqi Neurosurgeon continued to manage his neck injury in a stiff collar.

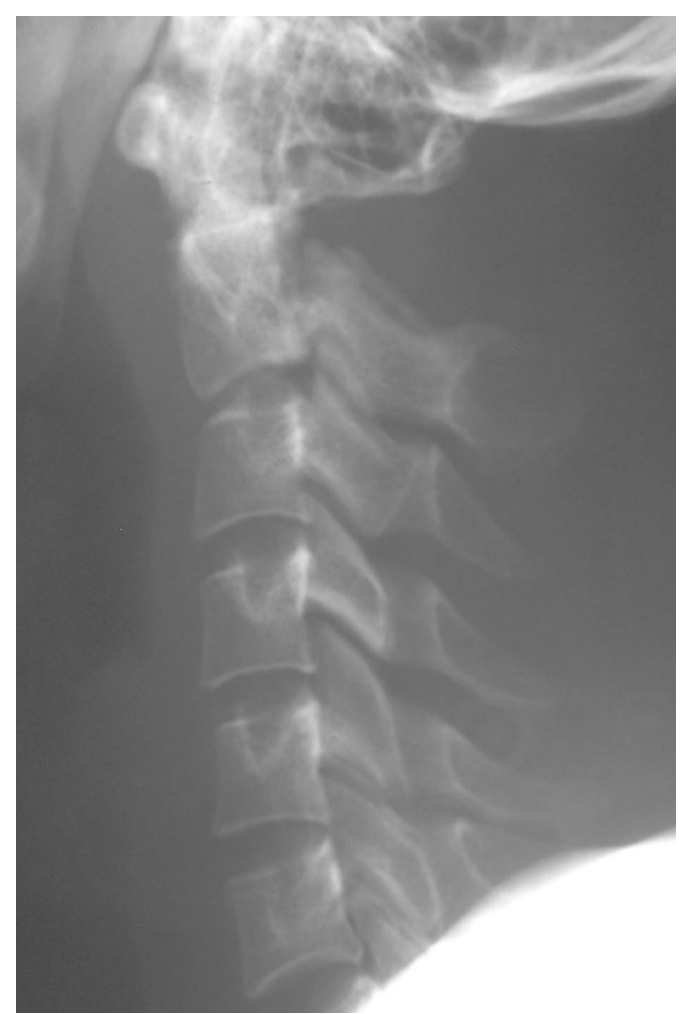

Fig 4. 'Hangmans' Fracture.

\section{Case 4}

A 21 year old American male soldier sustained an Axial Compression type injury to the cervical spine after diving into a shallow swimming pool. He was evacuated to MND(SE) Hospital by helicopter with his neck immobilised in a stiff collar. He complained of neck pain and had an incomplete quadriplegia with flaccid paralysis of all 4 limbs. He was breathing spontaneously and was fully conscious. Radiographs revealed a bifacetal dislocation of the C5 vertebra with an associated burst fracture of the body of C5 (Figure 5). It took approximately 2 hours from time of injury for the casualty to arrive at hospital. He received intravenous steroids within 20 minutes of arrival. The US neurosurgeon based in Baghdad was contacted and set off to our location by Blackhawk helicopter. However, it was estimated that he would arrive more than 6 hours after injury. The orthopaedic consultant at $\mathrm{MND}(\mathrm{SE})$ spoke with a British neurosurgeon at RCDM Birmingham who advised that reduction should be attempted as soon as possible and that waiting an extra 3 hours for the US neurosurgeon to arrive may further compromise the patient. Skull callipers were applied under local anaesthetic and manual reduction was attempted. The displacement was reduced partially, however complete reduction was not possible. Following partial reduction the casualty regained flexion at the elbows and was able to raise his arms off the bed. The US neurosurgeon brought a Halo Vest that was applied under local anaesthetic prior to aeromedical evacuation by Blackhawk helicopter to Baghdad.

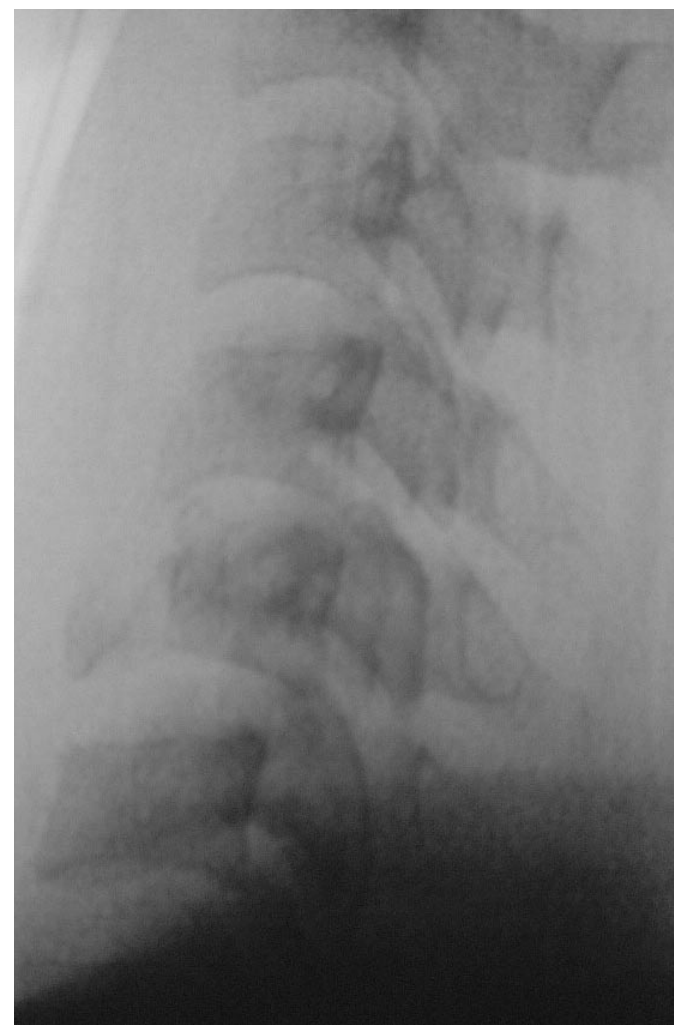

Fig 5. Radiographs showing a bifacetal dislocation of the C5 vertebra with an associated burst fracture of the body of C5.

\section{Case 5}

This 24 year old male British soldier was injured in a road traffic accident (RTA). He was an unrestrained passenger sitting in the rear of an ambulance that was returning from a hospital review appointment for a previous eye injury. The ambulance was involved in an RTA and subsequently rolled over. He was seen initially in Kuwait by an American surgical team who were based close to the scene of the accident. His main complaint was of neck pain and plain radiographs revealed a C7 anterior wedge fracture. A CT scan performed by the Americans, suggested a stable fracture pattern. He was transferred to MND (SE) Hospital with a stiff collar and aeromedical evacuation was organised. On arrival at RCDM Birmingham he was clinically assessed and flexion / extension cervical spine films were performed. These confirmed that the fracture was stable and no further orthopaedic intervention was required. No deterioration in his clinical picture was noted at review in the clinic. 


\section{Discussion}

"The patient with an acute cervical spine or spinal cord injury should be expeditiously and carefully transported from the site of injury to the nearest capable definitive care medical facility. The mode of transportation chosen should be based on the patient's clinical circumstances, distance from the target facility, and geography to be travelled and should be the most rapid means available."(3) This ideal is rarely achievable when transferring patients with cervical spine injuries from a military field hospital. The chain of evacuation is often very long; the journey can be over hazardous terrain and can involve multiple changes of mode of transportation. These factors must be taken into account in order "to provide high quality and timely healthcare for service personnel." (4)

Plain radiographs were the only form of skeletal imaging available at British Field Hospitals during this study period. Once a serious cervical spine injury was suspected following clinical and radiological examination, the casualty was immobilised until either definitive management or further imaging could be obtained back in the UK. Internal fixation provides the most stable treatment option (5), but as this kind of surgery is not possible, or desirable within a military field hospital, external control of the cervical spine must be employed.

Immobilisation of a cervical spine injury has moved on from the days of 'splint them where they lie' (6). It was recognised that movement of the neck after a serious injury before definitive treatment can be disastrous, primarily due to haematoma formation. The potential for movement is all the more whilst in transit (7-9). While it is now acknowledged that maintaining the head and neck in a neutral position is the ideal, there is ongoing debate about the exact positioning (10). For transfer between hospitals, the most stable method of external control of the cervical spine is the "Halo Brace" (11).

The "Halo Brace", was first introduced in the 1970s and has become a standard method of externally immobilising the neck. The Halo Ring is applied with 4 bolts that are screwed into the outer table of the skull using a Torque wrench supplied with the set. The Halo Ring is then attached by struts to a sheepskin lined plastic Vest, which covers the thorax (Figure 6). The Vest has anterior and posterior halves which Velcro together and is secured by straps. At least 2 people are required for the procedure, one to hold the head and one to apply the Halo. Five people are required to log roll the casualty and apply the Vest. In the Field Hospital there are sufficient staff available at any time to safely apply a Halo and Vest which takes approximately 45 minutes. Both Halos applications at the British Military Hospital were performed by experienced Consultant Orthopaedic

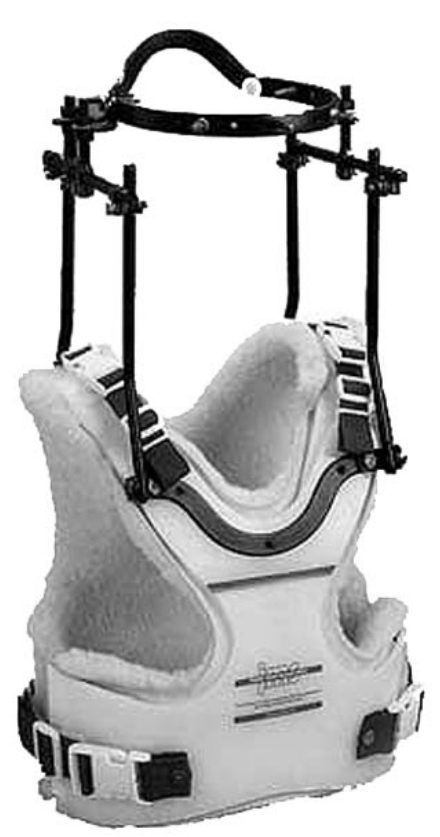

Fig 6. The Halo Ring.

Surgeons. Check radiographs must be taken to confirm satisfactory alignment without further displacement. Reduction of unifacetal cervical spine dislocations may be attempted with controlled traction using the Halo Ring itself. Bifacetal dislocations are reduced ideally after confirmation with MRI that the intervertebral disc is intact. Skin precautions are continued until the patients are mobile.

The Halo was first introduced as a method of conservative management of odontoid peg fractures (12), however it has since been used to manage other cervical spine fractures (13). Whilst the Halo does not give absolute stability $(5,14,15)$, it is unusual to have deterioration in neurology once it is fitted $(16,17)$.

It can be used as a definitive method of treating cervical spine injuries (18), enabling early mobilisation and rehabilitation (16). Its use augments the treatment of patients with multiple injuries (17). The Halo itself has the added advantage that it may be used to apply skeletal traction during the reduction of cervical spine injuries. It does have some complications. The most common are pin site infections or pressure sores related to the jacket. Over penetration of the pins has been reported and one author has reported a brain abscess associated with a Halo. However, the incidence of all complications is low $(13,15,16,19)$. The Halo is relatively easy to fit under local anaesthetic. There are several on the market, but there is little difference between them, based on stability and cervical movement in a cadaveric study (20). They are all MRI compatible.

The Field Surgery Pocket Book (1981) recommends that all "casualties with fractures of the cervical spine are evacuated with skeletal traction in situ, the neck being immobilised by small, firm pillows on either side"(21). 
Crutchfield introduced skeletal traction with tongs for cervical fractures in 1933 (17) and the basic concept has since remained essentially remained unchanged. However, a disadvantage of tongs is that this method is not possible during aeromedical evacuation.

One retrospective study suggested that when transferring a patient by either ground or air, there was no difference in outcome whether collar, blocks and tape or a Halo was used (9). This study is reassuring, however it was based at a regional spinal unit in Michigan where the distances (an average of 61 miles) and time spent in transit were a fraction of those experienced for evacuation on $\mathrm{Op}$ Telic. There are no further prospective studies available to guide us.

The civilian Neurosurgeons at RCDM Birmingham recommended fixation with a Halo Vest for our first case which prompted this retrospective review. CT scanning was not available to confirm the stability of the injury and RCDM Birmingham were concerned about the potential risk of developing a haematoma and subsequent neurological compromise during evacuation due to movement. A Halo Vest was flown out from the UK and applied before the casualty was evacuated back to the UK.

The methodology to identify all "serious cervical spine injuries" is potentially flawed but we believe it is the best possible information under the circumstances. The Military Field Hospital is the only Hospital available for all Coalition Forces in Southern Iraq and we believe that all serious neck injuries would have passed through our hospital before evacuation back to the UK. All injuries to the neck or cervical spine admitted to the British Military Hospital were identified from the hospital databases. In a hostile environment all injuries that prevent a soldier from performing his duties require hospitalisation, no matter how minor the injury. For this reason we believe that we have been able to identify virtually all injuries to the neck that prevent a soldier from working. Any fractures or dislocations of the cervical spine were diagnosed clinically and with radiographs. These injuries were considered to be "serious" and all others were considered "minor". As the tented hospital was not equipped with a CT or MRI scanner, we were unable to determine the stability of fractures and dislocations of the cervical spine. It is possible that we may have missed a ligamentous injury to the cervical spine but there were no casualties with "minor" neck injuries, admitted with neurological deficits at any time. None of our casualties suffered deterioration in their neurological condition following evacuation from Basra. We believe that readily available Halo Vests at the British Military Field Hospital allow timely application by a Consultant Orthopaedic Surgeon as soon as an unstable cervical spine injury is suspected and therefore permit early safe evacuation.

\section{Conclusions}

During the 14 months from the beginning of Op Telic, 47 patients were admitted with neck injuries to $\mathrm{MND}$ (SE) Hospital near Basra in Iraq. Five of these casualties sustained serious injuries to the cervical spine (3 fractures, one unifacetal dislocation and one bifacetal dislocation). Four of the injuries were potentially unstable $(8.5 \%$ of the total).

One US casualty needed a Halo that was flown in by a US surgeon from Kuwait. One UK casualty was managed in a Halo that was flown out from the UK. Of the three remaining casualties transferred without Halo stabilisation, one UK casualty was subsequently treated in a Halo; one UK casualty did not require any stabilisation and one Iraqi casualty was transferred to Basra where his management in a stiff collar was continued. His fracture would have been suitable for treatment with a Halo. These cases highlight the risk of sustaining an unstable cervical spine injury in a Military Theatre of Operation and the need for Halo Rings and Vests to be available at British Military Field Hospitals.

\section{Outcome}

In light of this experience, Halo Vests and Rings are now immediately available at British Field Hospitals.

\section{Acknowledgement}

The authors wish to thank Surg Cdr S Stapley RN for Figure 5 and Rozey Christian at BBraun Medical UK Ltd for Figure 6.

\section{References}

1. Swain A. Trauma to the spine and spinal cord. In: Swain A, Peyton R, Robertson C (eds). Cambridge Textbook of Accident and Emergency Medicine. Cambridge University Press 1997;pp. 510-532.

2. Leggate J, Driscoll P, Gwinutt C, et al. Trauma of the spine and spinal cord. In: Driscoll P, Skinner D (eds). Trauma Care: Beyond the Resuscitation Room. BMJ Books, 1998, pp. 135-55.

3. Hadley M. Transportation of patients with acute traumatic cervical spine injuries. Neurosurgery 2002 Mar; 50(3 Suppl):S18-20.

4. Armed Forces Overreaching Personnel Strategy, Chapter 3, Annex B: Personnel Strategy Guideline 19, Health Policy.

5. Bucci M, Dauser R, Maynard F, et al. Management of post-traumatic cervical spine instability: operative fusion versus Halo vest immobilization. I Trauma 1988;28(7):1001-6.

6. Meyer P, Sullivan D. Injuries to the Spine. Emerg Med Clin North Am 1984;2(2):313-29.

7. Geisler W, Wynne-Jones M, Jousse A. Early management of the patient with trauma to the spinal cord. Med Services f Can 1966;22:512-523.

8. Hachen H. Emergency transportation in the event of acute spinal cord lesion. Paraplegia 1974;12(1): 33-7.

9. Burney R, Waggoner R, Maynard F. Stabilization of spinal injury for early transfer. F Trauma 1989; 29(11):1497-9. 
10. Lorenzo R, Olson J, Boska M, et al. Optimal positioning for cervical immobilization. Ann Emerg Med 1996; 28(3): 301-8.

11. Johnson R, Hart D, Simmons E, et al. Cervical Orthoses. A study comparing the effectiveness in restricting cervical motion in normal subjects. $\mathcal{F}$ Bone foint Surg Am 1977;59(3):332-9.

12. Cloward R, Netter F. Acute Cervical Spine Injuries. Clinical Symposia 1980;32 (1):32-3.

13. Cooper P, Maravilla K, Sklar F. Halo immobilization of cervical spine fractures. Indications and results. f Neurosurgery 1979;50(5):603-10.

14. 11. White A, Panjabi M. The role of stabilization in the treatment of cervical spine injuries. Spine 1984; 9(5):512-22.

15. Glaser J, Whitehill R, Stamp W, et al. Complications associated with the halo-vest. A review of 245 cases. f Neurosurgery 1986;65(6):762-9.

16. Chan R, Schweigel J, Thompson G. Halo-thoracic brace immobilization in 188 patients with acute cervical spine injuries. $f$ Neurosurgery 1983;58(4): 508-15.
17. Heary R, Hunt C, Krieger A. Acute stabilization of the cervical spine by halo/vest application facilitates evaluation and treatment of multiple trauma patients. F Trauma 1992;33(3):445-51.

18. Richter D, Latta L, Milne E, et al. The stabilizing effects of different orthoses in the intact and unstable upper cervical spine: a cadaver study. F Trauma 2001;50(5):848-54.

19. Victor DI, Bresnan MJ, Keller RB. Brain abscess complicating the use of halo traction. $\mathcal{F}$ Bone foint Surg Am. 1973;55(3):635-9.

20. Mirza S, Moquin R, Anderson P, et al. Stabilizing properties of the halo apparatus. Spine 1997;22(7): 727-33.

21. Kirby N, Blackburn G. Field Surgery Pocket Book 1981. Her Majesty's Stationery Office: 191. 